\title{
What drives the drivers? A qualitative perspective on what motivates the crowd delivery workforce
}

\author{
Björn Asdecker \\ University of Bamberg \\ bjoern.asdecker@uni-bamberg.de
}

\author{
Florian Zirkelbach \\ University of Bamberg \\ florian.zirkelbach@gmail.com
}

\begin{abstract}
Crowd delivery is an emerging concept that adds flexibility to the last mile toward the customer. One factor that can hinder the success of such platforms is the availability of drivers. Against this background, this work conducted 27 interviews with current DoorDash, Postmates, and Amazon Flex drivers to gain deep insights into the motivations of these workers. Based on the observations, a selfdetermination theory (SDT)-based research model is derived. Despite some similarities, we find that the motivations of crowd delivery drivers differ from other crowds. For practitioners, it is important to consider these particularities to reach the critical mass of drivers and attract to most effective workforce. Scholars can use the provided qualitative perspective as a basis for future deductive-confirmatory studies.
\end{abstract}

\section{Introduction}

In today's retail market, an increasing number of people shop online. In the United States, for instance, e-commerce revenues increased more than sixty-eightfold between 1998 and 2015, jumping from 4.98 to 340.41 billion dollars [1]. From a logistics perspective, more e-commerce revenue leads to more shipments to be delivered. In fact, logistics service providers struggle to provide enough capacities to cope with the increasing highly volatile demand, especially during peak times [2]. Another major trend that is fueling the capacity bottleneck on the last-mile is the growing food delivery market [3], which requires flexible local transportation capacities to get the orders promptly to customers.

Against this background, logistics service providers, e-tailers, and restaurants are seeking innovative concepts that provide additional capacities and flexibility to the last mile. In that regard, a promising approach is crowd delivery, which is also known as crowdsourced delivery or crowdshipping.
Crowd delivery is a subtype of crowd logistics. It can be defined as a logistics service for the last mile, which is based on an IT-facilitated platform that matches supply and demand, thus allowing independent crowd workers perform the deliveries and be remunerated on a per-job basis. Among all crowd logistics forms, crowd delivery is considered to have the greatest disruptive potential [4], which is also reflected by the valuations of current crowd delivery startups. For instance, DoorDash landed \$535 million in funding, which equals a market valuation of around $\$ 1.4$ billion [5]. However, one crucial factor threatens the success story of any such service: crowd work availability. To become and remain successful they require a critical mass of workers to execute a competitive service and attract customers (e.g., [6],[7]). It is therefore necessary to investigate the factors that influence the drivers' motivations [7]. Against this background, this study addresses the following research-leading question:

What makes individuals participate as a driver in crowd delivery and to what extent?

So far, the existing literature has surveyed potential or actual drivers, performed discrete choice experiments, or analyzed real transactional data from a crowdshipping platform. In this paper, we advance this field by providing a qualitative-empirical perspective, which is - to the best of the authors' knowledge - the first such research with regard to crowd delivery. For this purpose, the available literature is reviewed to develop a theoretical framework, which is then used as the basis for the qualitative study. In total, 27 drivers have been interviewed. This study enables a better understanding of what drives individuals to be active crowd delivery drivers, which is essential for the success of a crowd delivery platform.

\section{Theoretical background}

To answer the research-leading question, we draw upon SDT, which is a behavioral theory about the 
motivations behind decisions that people make without external influences and interferences. Because crowd delivery is performed independently, that is, drivers autonomously decide when, where, and how much to work, SDT is considered to be a suitable theoretical background for this research.

SDT defines motivation as the underlying reason for a certain behavior [8]. Thus, this approach does not see motivation as a unitary concept that focuses on the amount of motivation that individuals have for certain behaviors; rather, it identifies three types of motivation that predict specific desired outcomes [9], which are listed as follows on a continuum from low to high levels of self-determination [10]: amotivation, extrinsic motivation, and intrinsic motivation.

Amotivation expresses disinterest in a task due to a feeling of helplessness and perceived incompetence. When a person is amotivated, he or she is wholly lacking self-determination and is experiencing discrepancy between the behavior and the outcome [8]. This leads to a hesitant attitude [10].

Extrinsic motivation entails performing a behavior for reasons that are external to the behavior itself. Extrinsically motivated individuals perform an activity due to pressure and/or obligation, which can come from the outside or the inside [9]. SDT distinguishes between four subtypes of extrinsic motivation that are listed as follows from high to low levels of regulation: (1) external motivation; (2) introjected motivation; (3) identified motivation; and (4) integrated motivation. External motivation involves engaging in a behavior only to achieve a desired outcome (e.g., receiving a reward or satisfying external pressure). In the case of introjected motivation, external controls are internalized but not accepted as such. With identified motivation, the behavior, which is considered to be important to achieve personally valued outcomes, is consistent with personal goals and therefore accepted. Finally, integrated motivation represents the full assimilation of the regulations that are completely adopted and embedded in an individual's behavior [10]. If integrated, a person identifies with the instrumentalized importance of the activity.

In contrast, intrinsic motivation refers to reasons that are inherent to the behavior. When a person is intrinsically motivated, he or she relies on the pleasure, fun, interest, enjoyment, and satisfaction that are obtained from engaging in an activity [9]. Intrinsic motivation evokes positive feelings of personal growth and supports psychological well-being. Therefore, intrinsically motivated behavior is expected to lead to higher levels of activity and to a higher quality of behavior compared to extrinsic motivation [8]. In the following, SDT will be used to classify the motivational factors that can be found in the literature.

\section{Literature review}

The conducted review considered both, the more specific crowd delivery literature and the more general crowdsourcing/sharing economy literature. Methodologically, the review follows the guidelines of Denyer and Tranfield (2009) who structured the research process in five steps: (1) question formulation; (2) locating studies; (3) study selection and evaluation; (4) analysis and synthesis; and (5) reporting and using the results [11]. The first step refers to the research question that is derived in the introduction. To locate the related studies we searched in six databases, namely, Business Source Ultimate (BS), Science Direct (SD), JSTOR (JS), Web of Science (WS), EconBiz (EB), and Google Scholar (GS). Table 1 provides an overview of the search terms and hits.

Table 1. Search terms and hits

\begin{tabular}{l|c|c|c|c|c|c}
\hline & BS & SD & JS & WS & EB & GS \\
\hline “crowd logistics" & 5 & 14 & 0 & 10 & 5 & 375 \\
\hline $\begin{array}{l}\text { "crowdsourced } \\
\text { logistics” }\end{array}$ & 2 & 1 & 0 & 4 & 0 & 14 \\
\hline "crowd delivery" & 0 & 7 & 0 & 0 & 0 & 55 \\
\hline "crowdshipping" & 5 & 16 & 0 & 10 & 4 & 130 \\
\hline $\begin{array}{l}\text { "crowdsourcing" } \\
\text { AND “partici*” }\end{array}$ & 19 & 12 & 3 & 98 & 19 & 165 \\
\hline $\begin{array}{l}\text { "crowdsourcing” } \\
\text { AND “motiv*” }\end{array}$ & 13 & 8 & 0 & 34 & 13 & 75 \\
\hline $\begin{array}{l}\text { "sharing economy" } \\
\text { AND “partici*” }\end{array}$ & 4 & 1 & 0 & 7 & 1 & 42 \\
\hline $\begin{array}{l}\text { "sharing economy" } \\
\text { AND “motiv*” }\end{array}$ & 4 & 1 & 0 & 3 & 2 & 14 \\
\hline
\end{tabular}

The further analysis was limited to accessible, peerreviewed scientific articles and conference papers in English. After a relevance check in the title and abstract, the shortlisted articles were completely read and assessed. To maintain the focus of this paper, only empirical (qualitative and quantitative) work that incorporates the perspective of crowd workers was taken into account. In total, we found five papers from the sharing economy literature, 13 articles from the crowdsourcing literature, and seven papers from the crowd delivery literature. Another 14 were identified by checking the relevant papers' references, providing a total of $5+13+7+14=39$ relevant papers.

\subsection{Motivating factors in crowdsourcing/ sharing economy}

For this study, 32 of the 39 relevant publications were identified in the crowdsourcing/sharing economy literature. Due to the strict page limitation of this paper 
it is impossible to present all of them here. However, when comparing the available literature the following five factors can be identified:

(1) Financial remuneration (e.g., [12],[13],[14]): Monetary compensation includes all types of immediate payment that is received for the completion of a task. The payments are either considered to be primary or secondary income and are the classic kind of external motivation.

(2) Skill development and job signaling (e.g., [15],[16],[17]): By performing tasks, crowd workers have the opportunity to acquire new skills or improve existing skills which can be transformed into delayed payoffs. One of those payoffs is to draw attention to one's abilities and to qualify for better-paid positions. It can be assumed that personal development and job signaling is consistent with personal goals and therefore accepted. Thus, it represents a form of identified motivation.

(3) Perceived autonomy (e.g., [16],[18],[19]): Autonomy refers to the degree of freedom in the execution of tasks. By definition, crowd workers independently manage their own schedules. They choose when to work and for how long. The concept of autonomy includes the freedom to make one's own decisions and to live out one's creativity. It is therefore considered to be an example of identified motivation.

(4) Community-relatedness (e.g., [20],[21],[22]): Human beings draw satisfaction from exchanges with other people. This can include informal communication but also stronger relationships such as making friends, which can arise through the job. The regulations of such behavior that are completely adopted and embedded in human behavior community-relatedness are considered to be an example of integrated motivation.

(5) Enjoyment (e.g., [23],[24],[25]): While performing tasks, workers can feel joy. This joy is especially due to the versatility of the tasks and the satisfaction that results from the completion of the tasks. Since people engage in the activity for pleasure and fun, it is considered to be an intrinsic motivation.

These motivational factors will now be compared with the ones that have been reported in the more specific field of crowd delivery.

\subsection{Motivating factors in crowd delivery}

Despite being a crucial success factor, only seven empirical papers contribute to the issue under investigation. Comparing the crowd delivery publications with the more general crowdsourcing and sharing economy literature reveals commonalities and differences. There is agreement on financial remuneration (e.g., [26],[27]), perceived autonomy (e.g., [28],[29]), and enjoyment (e.g., [29],[30]). Differences exist with regard to communityrelatedness. It appears as if drivers relate more to the consignees than other crowd workers ([28],[31]). For instance, Devari et al. (2017) emphasize that "[...] $72 \%$ [...] will accept or deliver a product only for or to their friends or close friends” ([31], p. 109). In addition, some authors mention the contributions to environmental sustainability as motivations ([30],[32]). For instance, Marcucci et al. (2017) report that "[...] students are willing to support crowdshipping if environmental benefits can be measured and certified” ([32], p. 841). Thus, environmental sustainability is considered to be a form of identified motivation. The factor skill development and job signaling has not yet been discussed in the crowd delivery literature but shall not be ruled out at this stage. Thus, the following six factors were used as the basis for the qualitative investigation in the following section: (1) financial remuneration; (2) perceived autonomy; (3) enjoyment to deliver; (4) community-relatedness; (5) skill development and job signaling; and (6) environmental sustainability.

\section{Qualitative study of factors that motivate the crowd delivery workforce}

This chapter describes the methodology and sample characteristics before presenting the obtained results.

\subsection{Methodology}

We used expert interviews to gather specialized knowledge that is only available to a specific group of individuals. To be considered an expert, individuals had to be a driver for at least six weeks for either DoorDash, Postmates, or Amazon Flex - three of the leading platforms in the United States. Participants were recruited on Facebook because drivers meet and communicate with each other in groups such as "Atlanta Postmates" or "Amazon Flex Drivers Los Angeles". To join the groups, the authors sent a message to one of the groups' admins to explain the purpose for joining and receiving permission to post the study invitation. As an incentive to participate, we offered a $\$ 1$ donation for every completed interview to a charitable project on GoFundMe.com. In addition, anonymity was guaranteed to the participants. In total, the study invitation was posted in 14 groups.

Because this research wants to develop a deeper understanding of what makes individuals participate in crowd delivery while relying on motivational factors from the available literature, semi-structured interviews were used as the data collection method. 
Semi-structured interviews follow a guide of preformulated questions but allow for additional questions to gather further information if new ideas are brought up. The interview guide consisted of 33 mostly openended questions that can be divided into three categories: (1) 18 questions about the driver and his/her background (e.g., "How old are you?” and "Do you have kids? If yes, how many?”); (2) nine questions about motivational factors (e.g., "What would you say is your motivation or reason to do this job?" and "Are there any other motivational factors or reasons you can think of?”); and (3) six additional side-questions which were asked if appropriate (e.g., "Are you following some kind of patterns when you work?" and "What kind of people would you recommend working for those delivery platforms?"). Prior to the field phase the practicability and understandability of the questions were tested during two trial interviews.

The interviews were conducted using Facebook's instant messenger. Instant messaging interviewing "[...] allows synchronous and semi-private interaction and can automatically record the interaction text. The ad hoc conversational nature of [instant messaging] interviews lets them resemble oral interviews” ([33], p. 259). This method cannot record facial expressions or acoustic cues, but participants can instead use emoticons, punctuation marks, or modifications such as bold or capitalized text to express themselves. In addition, the visual anonymity may enhance the selfdisclosure of participants. To employ the method, interviewees must be familiar with online communication [33], which is the case with crowd delivery workers who regularly use their smartphones and platform apps.

The interview data were analyzed as described in Mayring (2000) [34]. More specifically, this research uses the method of deductive category application. Herein, prior formulated theoretical derived categories are connected with the qualitative data. Mayring (2000) structures the research process in six stages: (1) research question(s); (2) theoretical based definition of the aspects of analysis, main categories; (3) theoretical based formulation of definitions; examples and coding rules for the categories; (4) revision of categories and coding agenda; (5) final working through the texts; and (6) interpretation of results, quantitative steps of analysis (e.g., frequencies) [34]. With regard to the first step, the research question was formulated in the introduction of this paper. For the second step, the literature was reviewed, leading to six main categories. In the third step, a coding agenda was set up by the second author to facilitate the classification of the specific interview parts. In the fourth step, the derived coding agenda was used to code the interviews, which was repeated after some time. Then, in the fifth step, the first author used the revised coding agenda to go over the data again. The results (step 6) will be presented after the description of the sample in section 4.3.

\subsection{Sample characteristics}

In total, 27 instant messaging interviews were conducted in January 2019 (avg. length: 50 minutes). On average, the participants had been crowd delivery workers for 14.4 months. The participants are from 14 different cities in 11 different states. The final sample consisted of 20 women (74.1\%) and seven men (25.9\%). This does not correspond to the gender distribution in the total population, which is why particular attention has been paid to gender-specific anomalies during data analysis. However, only a single peculiarity was observed. It appears that women value the flexibility of controlling one's own schedule more than men. One reason for this may be that crowd delivery is particularly attractive for young mothers seeking a work-life balance. Other crowd delivery studies have not reported on gender-specific motivational differences. Furthermore, in a more general context, SDT does not address gender-specific differences, and a meta-study on this issue has not reported different results [35]. For these reasons, we consider the unequal gender distribution to be of minor relevance.

With regard to relationship status, 14 (51.9\%) participants are single, seven (25.9\%) are in a relationship and six (22.2\%) are married. More than half of the respondents have children (51.9\%). With respect to education, 15 (55.5\%) held high school diplomas, nine (33.3\%) held bachelor's degrees, and two held master's degrees (7.4\%). One interviewee was still attending high school. Many of the participants indicated that they drive for multiple platforms. In such cases, we determined their primary platform $\quad(\mathrm{D}=$ DoorDash, $\quad \mathrm{P}=$ Postmates, and $\mathrm{AF}=$ Amazon Flex) and related the questions to it. Table 2 provides an overview of the study participants. Because anonymity was assured, pseudonyms are used.

\subsection{Results}

Drawing on the previously derived typology of the potential motivational factors in crowd delivery, participants have been explicitly asked about their motivations and why they joined the crowd delivery workforce. The semi-open interviews gave the respondents the opportunity to identify other important factors at any time. Thus, two categories were added. The results of the analysis will be presented using 
direct citations from the interviews to underpin the line of reasoning.

\section{Table 2. Characteristics of Study Participants}

\begin{tabular}{l|c|c|c}
\hline \multicolumn{1}{c|}{$\begin{array}{c}\text { Name } \\
\text { (Platform, Age) }\end{array}$} & $\begin{array}{c}\text { Active } \\
\text { months }\end{array}$ & $\begin{array}{c}\text { Weekly } \\
\text { hours }\end{array}$ & $\begin{array}{c}\text { Fulltime } \\
\text { driver? }\end{array}$ \\
\hline Amanda (P, 41) & 20 & 27.5 & yes \\
\hline Bernadette (D, 27) & 6 & 27 & yes \\
\hline Brigitte (AF, 56) & 16 & 21 & yes \\
\hline Cheryl (D, 37) & 7 & 20 & yes \\
\hline Clark (AF, 29) & 2 & 8 & no \\
\hline David (D, 26) & 24 & 40 & yes \\
\hline Diana (D, 41) & 7 & 25 & no \\
\hline Henriette (AF, 57) & 12 & 20 & no \\
\hline Irma (AF, 33) & 14 & 29 & no \\
\hline Jacky (AF, 27) & 22 & 30 & yes \\
\hline Jeanette (D, 21) & 7 & 27.5 & yes \\
\hline John (AF, 26) & 51 & 20 & yes \\
\hline Josephine (AF, 25) & 15 & 45 & yes \\
\hline Juliette (P, 20) & 9 & 5.5 & no \\
\hline Larissa (P, 40) & 10 & 27.5 & yes \\
\hline Lisa (AF, 28) & 12 & 30 & yes \\
\hline Louise (AF, 37) & 6 & 17.5 & no \\
\hline Lucy (P, 37) & 12 & 35 & no \\
\hline Lynette (AF, 39) & 26 & 20 & no \\
\hline Michael (D, 45) & 12 & 50 & yes \\
\hline Mona (AF, 40) & 30 & 32.5 & yes \\
\hline Norman (AF, 32) & 14 & 16 & no \\
\hline Peter (P, 32) & 13 & 35 & yes \\
\hline Rosa (AF, 49) & 24 & 70 & yes \\
\hline Tina (P, 28) & 3 & 12.5 & no \\
\hline Tom (AF, 47) & 8 & 17 & no \\
\hline Wendy (AF, 51) & $\mathbf{1 4 . 4}$ & $\mathbf{2 7 . 8}$ & yes \\
\hline Average & & & - \\
\hline & & & \\
\hline
\end{tabular}

4.3.1. Financial remuneration. Financial remuneration is by far the most mentioned motivational factor. In total, $88.9 \%(n=24)$ of all participants stated the importance of monetary compensation as a response to the question regarding why they participate in crowd delivery. Tina responded to the follow-up question if there are any other motivational factors for her to participate as follows: "No, I do it for money and that's the only motivation."

Even though full-time and part-time drivers both participate for monetary compensation, they have different underlying reasons. Full-time workers try to make a living to pay their bills and feed their families. Because eight of the 16 full-time drivers are single, crowd delivery is often their only source of income, and David even considers it as vital to "[...] survive". In contrast, most part-time drivers see crowd delivery as a way build up their financial reserves. Part-time driver Clark noted the following: "I have a large family, and my full time job pays enough to live month to month. If we ever have any kind of emergency it takes us months to financially recover. I'm trying to build a savings account." Lucy, with a self-reported annual household-income of $\$ 204,000$ works an additional 25-30 hours per week to earn "[e]xtra money for retirement and discretionary income."

4.3.2. Perceived autonomy. The second most important motivational factor is perceived autonomy, which was mentioned by $59.3 \% \quad(n=16)$ of the participants. David said: "If I could have a "traditional" job that allowed me the flexibility that I currently have, I would do it in a heartbeat."

It appears that the autonomy that was mentioned by the respondents comprises two dimensions: first the freedom to control one's own schedule (Jeanette, Bernadette, Juliette, Louise, and Diana) and second to be one's own boss (Michael, Jeanette, Henriette, and Norman); that is, the lack of hierarchy one has to fit in. The first answer of Lisa to the question why she participates in crowd delivery synthesizes both dimensions: "Honestly, the freedom. You can take time off when you want for vacations, holidays, etc. I don't have to answer to anyone.”

4.3.3. Enjoyment to deliver. During the interviews $55.5 \%(n=15)$ of all participants state that they actually enjoy the activity, and an additional $29.6 \%$ $(n=8)$ confirmed that they enjoy it at least sometimes. The majority enjoys the uncomplicated nature of the job and expressed how easy it is. David even said that "[i]t is the easiest job you can have to pay the bills where you put in the least amount of effort and care." This was also one of the reasons for Wendy, who was burned out from her old job before starting as a fulltime crowd delivery driver: "[The job is] easy peasy without having too much analytical thought process. [I was] so tired of thinking and being analytical."

However, the ease of the job is not the only enjoyment factor. For instance, Mona, Lisa, and Diana like getting to know the areas of their cities that they had not spent much time in or had not even heard about before. Some drivers gained enjoyment from the ability to listen to their own music or podcasts during work (Larissa, Irma, Louise, and Henriette), simply driving their cars (Michael, Jeanette, Bernadette, and Juliette), the ability to take a passenger with them while working (Jeanette and Norman), and getting out of the house now and then (Larissa). Josephine and Henriette like to make a competition out of the job by trying to fulfill as many deliveries as possible in a certain amount of time. For Tom, his enjoyment is so high that he would work as a crowd delivery driver without any monetary compensation whatsoever. He summarized this with 
the following words: "[...] experiences, things you can learn, things you can see, people you can meet, etc.”

4.3.4. Community-relatedness. Another source of motivation can come from the community of drivers that allow one to feel a part of a collective action and relate to each others, which increases one's sense of belonging and commitment. The exchange with other drivers usually takes place in online forums and social media groups. However, only a minority of participants $(11.1 \%, n=3)$ considered the driver community as a source of motivation. Amanda, Mona and Irma stated that they use online groups to socialize and reported that they have become friends with other drivers. The social exchange with other drivers gives them the feeling of belonging to this group. The overwhelming majority, however, did not consider the driver community as a motivating factor but as a means to improve their overall crowd delivery experience. For several respondents, the forums and groups are a way to determine road and weather conditions (Michael, John, Lisa, and Irma) and how to become more successful (Bernadette, Louise, and Henriette). Others use it as a pastime while waiting for the next delivery request (John and Peter). When directly asked whether they would quit if there were no such communities, no one agreed, which demonstrates the marginal relevance.

Another community that a driver can relate to is the group of consignees. Delivering can be an important task, particularly for the elderly, sick, and/or immobile, because it can be the only option to remain independent. Some participants mentioned that they were motivated by the recipients of their deliveries $(n=8,29.6 \%)$. Jeanette and Diana "[...] love the interaction [...]" in general, whereas Wendy just wants her "[...] customers to be happy." The idea to give something back to the community led Rose to hand out handwritten personal notes for customers if she felt the consignee needed some encouragement. However, almost as many ( $n=7,25.9 \%)$ explicitly stated that they do not want to interact with customers for various reasons. For instance, Cheryl reported that she suffers from anxiety disorders and "[...] love[s] the fact that interaction with the customers is minimal.” Minimal customer interaction also motivates Henriette to do the job: "I've done nails for so long. I am sick of the public.” Josephine, Lisa, and Peter consider human interaction to be a burden that ultimately slows down the delivery process and decreases their productivity.

4.3.5. Skill development and job signaling. While some of the respondents reported that there are customer service skills (Lucy, Larissa, Bernadette,
Juliette, and Norman), time management skills (Jacky, Lucy, Lisa, Henriette, and Norman), navigational skills (Jacky, Rosa, Irma, Henriette, and Lynette) and selforganizational skills (John, Henriette, Clark, and Norman) involved in being a crowd delivery driver, none of the respondents agreed that they started to work as a crowd delivery driver to develop skills or for job signaling. Only three participants would include the job as a reference in their resume to apply for a job in the future (John, Jeanette, and Diana). In fact, Juliette would even conceal it in her curriculum vitae because she believes that employers might think she became a crowd delivery driver just because of a lack of other skills. This sentiment is supported by Louise who recommends the job to "[p]eople with maybe not enough skills or education to get a higher paying job [...]”.

4.3.6. Environmental sustainability. None of the interviewees considered environmental sustainability to be a motivational factor. Only two even consider crowd delivery as beneficial for the environment. In that regard, Wendy noted: "Yes, I think it's environmentally friendlier because [...] many of the standard delivery systems... USPS, FedEx, UPS... require a customer to be there and won't leave a package at their door... [...] And like I said, my little car gets better mileage than those big trucks 今.?" However, the overwhelming majority of the respondents had either not thought about the environmental impacts (Amanda, Mona, Juliette, Peter, Tom, Louise, Henriette, and Clark) or doubt that crowd delivery has a positive impact (Josephine, Lucy, John, Lisa, Irma, Norman, Lynette, and Diana). Norman, for instance, believes that crowd delivery is an inferior alternative from an environmental point of view: "No, because more cars are on the road and causing more carbon emissions vs. one mail truck delivering to multiple locations. Now you have way more cars out driving doing deliveries.”

4.3.7. Additional factors. During the analysis of the interviews two further factors emerged that have not yet been discussed in the scientific crowd delivery literature in this form:

(1) Platform usability and support: Several respondents (John, Amanda, Clark, Lisa, Josephine, and Rosa) emphasized that they expect a certain user friendliness and ease of use, which makes the delivery experience positive. This can be seen, for example, in the differences between the platforms that were examined. With the transaction-based platforms DoorDash and Postmates, drivers can deliver as soon and as long as there are transportation requests. In 
contrast, drivers for the batch-based platform Amazon Flex have to acquire so-called "blocks" before they can actually deliver. John directly expressed his displeasure with that procedure: "What I HATE is how delivery blocks are acquired.” In that regard, Clark added: "My biggest frustration has been with the lack of availability since the new year started, along with Amazon's system to signing up for blocks [...]." Josephine is also frustrated about the block acquisition: "[...] it's impossible to get a block. When you do finally get a block you have to wait over an hour sometimes to get your packages.” Accordingly, the main challenge is that Amazon publishes available blocks at random times during the day. To have the opportunity to work, it is necessary to check the app regularly to secure delivery jobs (John and Lisa). The answers showed that the interviewees expect the platform's app to help and support the drivers to do their job as effectively as possible. In that regard, Amanda, who also works for UberEats, noted: "I like UberEats because [...] the platform is more userfriendly for drivers. But Postmates is hands-down the busier of the two." Rosa, an Amazon Flex driver who also works for other platforms, provides a good example: "Postmates and DoorDash do not have adequate customer service. Their app does not allow me to contact the customer prior to a certain point in the driving process. However, sometimes there are questions about replacements for products that are ordered and are unavailable and need substitutions. This is extremely frustrating for both the customer and the delivery driver." Thus, we conclude that while platform usability and support are not direct forms of intrinsic or extrinsic motivations, they can avoid amotivation and hence support crowd delivery participation.

(2) Platform addictiveness: During the interviews the vast majority of participants $(88.0 \%, n=24)$ justified their continuity in performing deliveries with some kind of addictive behavior. For instance, Juliette and Jacky stated that they were on a "roll" and worked past midnight on several occasions because there was still customer demand. Louise had similar experiences, stating that sometimes she woke up at $4 \mathrm{am}$ to do an Amazon Flex block prior to her regular job and claim another block afterwards. She even thought about calling in sick just to do additional blocks. Another example is from Henriette who states: "I notice I can't stop looking at the app. Always looking for the next job.” In addition, Clark noted: "I'm actually having a really difficult time relaxing. I feel I need to be more productive or making more money. Truth be told, it's become a problem.”

The participants also speculated on the cause of a crowd delivery platform's addiction potential. The two most frequently mentioned reasons were the drive to earn more money (Jacky, Mona, Larissa, Lisa, Irma, Bernadette, Juliette, Tom, Clark, Wendy, and Diana) and the constant use of their smartphone and the respective platform app (Rosa, Irma, Brigitte, Henriette, Lynette, and Diana). Based on these observations, we conclude that platform addictiveness may not be a direct source of motivation; instead, it may be a variable that positively affects the strength between the level of extrinsic motivation and crowd delivery participation.

\subsection{Discussion}

The study gives a strong indication of which factors have motivating effects and which do not. These findings will be used to derive specific research propositions (RP), which will finally be transferred into a research model.

The most important motivational factor is financial remuneration. This finding is consistent with available crowdsourcing/shared economy publications (e.g., [13],[14]) and crowd delivery publications (e.g., [27],[28]). Furthermore, the second most important factor is motivation through the perceived autonomy, which has been previously noted. The autonomy particularly refers to the freedom to control one's own schedule and to be one's own boss, which further supports the findings from the crowdsourcing and crowd logistics literature [18],[28]. This study also confirms intrinsic motivations through enjoyment which has been mentioned in other contexts (e.g., [23],[24]) and in crowd delivery [29],[30]. Unlike other publications, however, this study finds that the joy of being a crowd delivery worker does not come from the feeling of psychological empowerment [22] or the feeling of success [23], but primarily comes from the simplicity of the task. This finding supports Ye and Kankanhalli (2017) who observed that crowdsourcing participants are generally more willing to complete cognitively less demanding tasks [16].

The data on participating in crowd delivery for the sake of community-relatedness is highly controversial. Only a small minority of interviewees considered the driver community to be a source of motivation. The relatedness to the consignees appears to be more important. Slightly fewer than one third of respondents indicate that they are motivated by customers, which confirms the results of Devari et al. (2017) [28] and Le and Ukkusuri (2018) [31]. However, about the same number of respondents stated that they do not relate this job primarily because they like being alone and are able to do it without intensive social interactions. Due to multitude of different statements, we conclude that community-relatedness is only a selective motivational 
factor that highly depends on a driver's personality, which we therefore consider a moderating factor.

A factor that has not yet been considered in the identified scientific literature is the influence of platform usability and support. According to our findings, the participants expect a certain userfriendliness of the platform in order to make the work experience positive and to keep amotivation low. This finding supports recent reports in more practitioneroriented anecdotal work [36]. Another factor that emerged from the interviews is platform addictiveness.

Brabham (2010) reported the addiction to the community as a motive for participation [15]. In crowd delivery, the reasons for the addictive behavior are rooted in the permanent use of the smartphone and the need to make more money rather than the community. It seems that the addictive behavior acts as a catalyst for extrinsic motivation through financial rewards and intrinsic motivation through enjoyment. Like with addictive substances, too much of it can do damage. Several study participants stated that platform addictiveness became a personal problem for them. Research suggests that the frequent use of smartphone applications can lead to stress, sleep disturbances, and symptoms of depression [37]. In their current state, the only limitation of an app to prevent overuse is a lack of demand. As long as customers order items, there is a constant stream of available tasks that may cause participants to keep delivering. To conclude, the platforms' smartphone applications may on the one hand encourage users to feel productive and happy, but on the other hand, they can lead to stress and frustration if used too much. This finding indicates an inverse U-shaped moderating effect.

The two factors of environmental sustainability and skill development and job signaling do not play fundamental roles. This result contradicts the crowd logistics literature, which assumes that drivers can be motivated by making positive environmental impacts [30],[32], as well as the crowdsourcing/sharing economy literature (e.g., [15],[21]). Obviously, the simplicity of the delivery task is not sufficient to realize meaningful skill development or job signaling benefits. To conclude, this study leads to the following research propositions (RP):

RP1: The perceived platform usability and support positively relates to crowd delivery participation.

RP2: A driver's financial remuneration positively relates to crowd delivery participation.

RP3: A driver's community-relatedness positively relates to crowd delivery participation.

RP4: A driver's perceived autonomy positively relates to crowd delivery participation.
RP5: The driver's enjoyment to deliver positively relates to crowd delivery participation.

RP6: The influence of financial remuneration on crowd delivery participation is moderated by platform addictiveness such that it will increase for high levels of platform addictiveness.

RP7: The influence of the enjoyment to deliver on crowd delivery participation is moderated by platform addictiveness such that it will be stronger for medium levels of addictiveness and weaker for high levels of addictiveness.

RP8: The influence of community-relatedness on crowd delivery participation is moderated by the driver's personality such that it will be stronger for individuals with a social personality type.

Figure 1 summarizes the proposed research model.

\section{Conclusion}

Crowd delivery is an emerging phenomenon that is likely to become more important in the digital age ahead. A crucial aspect for the success of such platforms is the participations of workers. This paper reviews the existing knowledge about factors that motivate crowd workers and takes a qualitative perspective to develop a thorough understanding in the specific context of crowd delivery. Drawing on SDT, we argue that performing crowd deliveries is influenced by different types of motivation. While theorizing on participation in the crowd delivery workforce, we find that the set of motivators in crowd delivery differs from those of other cases. This topic therefore requires standalone research. Our research points to the influence of constructs that have not been considered in the crowd delivery literature, i.e., platform usability and support as well as platform addictiveness, and therefore expands the field of investigation. Based on the observations we derived a research model with a total of eight research propositions to stimulate further deductiveconfirmatory studies. The identified factors can also be used by platform operators to increase the motivations of their workforce. Gaining such knowledge is a cornerstone of a supply management strategy that ensures the availability of drivers and the functioning of the logistics system.

The limitations of this study include interviewing members of only three crowd delivery platforms, namely, DoorDash, Postmates, and Amazon Flex. There are other crowds, such as Uber Eats, with other or additional motives. There may also be a geographic bias, as we only considered drivers from urban 


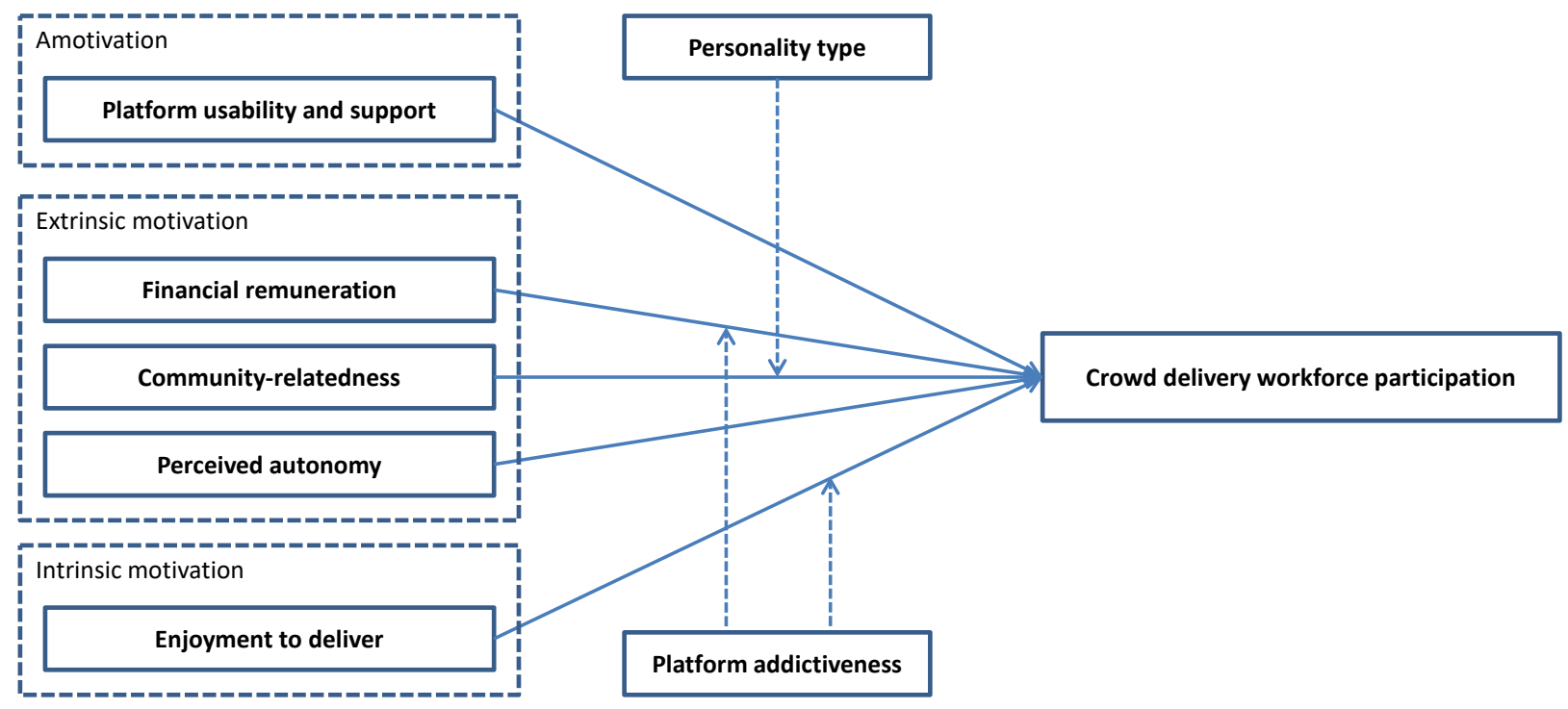

Figure 1. SDT-based research model

metropolitan areas. In addition, only drivers from the United States were interviewed, neglecting potential cultural influences. Besides, this work could be criticized because the sample did not reflect the gender distribution in the total population, although only minor gender-specific characteristics were found in the evaluation.

While the derived research model provides a good starting point, additional studies should be undertaken to provide further insights into why people are motivated to deliver. This may, for instance, include questions regarding how demographic (e.g., age) or economic factors (e.g., household income) could mitigate the various motivations to work as a crowd delivery driver. Such questions have not been answered by this research but are necessary to further strengthen and improve the proposed model.

\section{References}

[1] United States Census Bureau, "Estimated Annual U.S. Retail Trade Sales - Total and E-commerce (19982015)“, https://www.census.gov/data/tables/2015/econ /e-stats/2015-e-stats.html, 2018.

[2] Lim, H. and N. Shiode, "The impact of online shopping demand on physical distribution networks: a simulation approach", International Journal of Physical Distribution \& Logistics Management, 41(8), 2011, pp. 732-749.

[3] Hirschberg, C., A. Rajko, T. Schumacher, and M. Wrulich, "The changing market for food delivery". https://www.mckinsey.com/industries/high-tech/ourinsights/the-changing-market-for-food-delivery, 2016.

[4] Carbone, V., A. Rouquet, and C. Roussat, "The Rise of Crowd Logistics: A New Way to Co-Create Logistics
Value”, Journal of Business Logistics, 38(4), 2017, pp. 238-252.

[5] Somerville, H., "DoorDash raises \$535 million in funding round led by Softbank", https://www.reuters.com/article/us-doordash-

funding/doordash-raises-535-million-in-funding-roundled-by-softbank-idUSKCN1GD64K, 2018.

[6] Frehe, V., J. Mehmann, and F. Teuteberg, "Understanding and assessing crowd logistics business models - using everyday people for last mile delivery”, Journal of Business \& Industrial Marketing, 32(1), 2017, pp. 75-97.

[7] Castillo, V. E., J.E. Bell, W. J. Rose, and A. M. Rodrigues, "Crowdsourcing Last Mile Delivery: Strategic Implications and Future Research Directions”, Journal of Business Logistics, 39(1), 2018, pp. 7-25.

[8] Deci, E. L. and R. M. Ryan, Intrinsic Motivation and Self-Determination in Human Behavior, Springer US, Boston, MA, 1985.

[9] Deci, E. L. and R. M. Ryan, "Self-determination theory: A macrotheory of human motivation, development, and health", Canadian Psychology/Psychologie canadienne 49(3), 2008, pp. 182-185.

[10] Gagné, M. and E. L. Deci, "Self-determination theory and work motivation", Journal of Organizational Behavior, 26(4), 2005, pp. 331-362.

[11] Denyer, D. and D. Tranfield, "Producing a systematic review”, in D.A. Buchanan and A. Bryman (Ed.), "The Sage handbook of organizational research methods”, Sage, Los Angeles, 2009, pp. 671-689.

[12] Mahmod, M., N. Na'in, R. Ahmad, S. C. Chit, and A. Habbal, "Interlinked Motivation Model to Use Mobile Crowdsourcing Platforms Among Low-Income Citizens”, Pertanika Journal of Science \& Technology 25(S), 2017, pp. 99-108. 
[13] Rogstadius, J., V. Kostakos, A. Kittur, B. Smus, J. Laredo, and M. Vukovic, "An Assessment of Intrinsic and Extrinsic Motivation on Task Performance in Crowdsourcing Markets”, Proceedings of the Fifth International AAAI Conference on Weblogs and Social Media, 2011, pp. 321-328.

[14] Zhao, Y. and Q. Zhu, "Evaluation on crowdsourcing research: Current status and future direction", Information Systems Frontiers 16(3), 2014, pp. 417434.

[15] Brabham, D. C., "Moving the crowd at threadless: Motivations for participation in a crowdsourcing application”, Information, Communication \& Society, 13(8), 2010, pp. 1122-1145.

[16] Ye, H. and A. Kankanhalli, “Solvers' participation in crowdsourcing platforms: Examining the impacts of trust, and benefit and cost factors", The Journal of Strategic Information Systems, 26(2), 2017, pp. 101117.

[17] Jiang, L., C. Wagner, and B. Nardi, "Not Just in it for the Money: A Qualitative Investigation of Workers' Perceived Benefits of Micro-task Crowdsourcing”, Proceedings of 48th Hawaii International Conference on System Sciences (HICSS), 2015, pp. 773-782.

[18] Teodoro, R., P. Ozturk, M. Naaman, W. Mason, and J. Lindqvist, "The motivations and experiences of the ondemand mobile workforce”, Compilation publication of CSCW'14 Proceedings \& CSCW'14 Companion, 2014, pp. 236-247.

[19] Deng, X. and K. D. Joshi, "Why Individuals Participate in Micro-task Crowdsourcing Work Environment: Revealing Crowdworkers' Perceptions”, Journal of the Association for Information Systems 17(10), 2016, pp. 648-673.

[20] Kaufmann, N., T. Schulze, and D. Veit, "More than fun and money. Worker Motivation in Crowdsourcing - A Study on Mechanical Turk", Proceedings of the Seventeenth Americas Conference on Information Systems (AMCIS), 2011, pp. 1-11.

[21] Baumann, C. and H. Gewald, "What Motivates Crowdsourcing Contributors? A Cross-Platform Comparative Analysis”, Proceedings of the TwentySecond Pacific Asia Conference on Information Systems (PACIS), pp. 1-13.

[22] Goncalves, J., S. Hosio, J. Rogstadius, E. Karapanos, and V. Kostakos, "Motivating participation and improving quality of contribution in ubiquitous crowdsourcing”, Computer Networks, 90(1), 2015, pp. 34-48.

[23] Väätäjä, H., E. Sirkkunen, and M. Ahvenainen, “A Field Trial on Mobile Crowdsourcing of News Content: Factors Influencing Participation”, in P. Kotze, G. Marsden, G. Lindgaard, J. Wesson, and M. Winckler (Ed.), "Human-Computer Interaction -- INTERACT 2013, Springer, Berlin/Heidelberg, pp. 54-73.

[24] Sun, Y., Y. Fang, and K. H. Lim, "Understanding sustained participation in transactional virtual communities”, Decision Support Systems, 53(1), 2012, pp. 12-22.
[25] Sun, Y., N. Wang, and Z. Peng, "Working for one penny: Understanding why people would like to participate in online tasks with low payment", Computers in Human Behavior, 27(2), 2011, pp. 10331041.

[26] Serafini, S., M. Nigro, V. Gatta, and E. Marcucci, "Sustainable crowdshipping using public transport: A case study evaluation in Rome”, Transportation Research Procedia, 30(1), 2018, pp. 101-110.

[27] Ermagun, A. and A. Stathopoulos, "To bid or not to bid: An empirical study of the supply determinants of crowd-shipping”, Transportation Research Part A: Policy and Practice, 116(1), 2018, pp. 468-483.

[28] Le, T. V. and S. V. Ukkusuri, "Crowd-shipping services for last mile delivery: Analysis from survey data in two countries”, 97th Annual Meeting Transportation Research Board, 2018, https://arxiv.org/pdf/1810. 02856.

[29] Miller, J., Y. Nie, and A. Stathopoulos, "Crowdsourced Urban Package Delivery”, Transportation Research Record: Journal of the Transportation Research Board, 2610(1), 2017, pp. 67-75.

[30] Paloheimo, H., M. Lettenmeier, and H. Waris, "Transport reduction by crowdsourced deliveries - a library case in Finland”, Journal of Cleaner Production, 132(1), 2016, pp. 240-251.

[31] Devari, A., A. G. Nikolaev, and Q. He, "Crowdsourcing the last mile delivery of online orders by exploiting the social networks of retail store customers”, Transportation Research Part E: Logistics and Transportation Review, 105(1), 2017, pp. 105-122.

[32] Marcucci, E., M. Le Pira, C. S. Carrocci, V. Gatta, and E. Pieralice, "Connected shared mobility for passengers and freight: Investigating the potential of crowdshipping in urban areas", Proceedings of the 5th IEEE International Conference on Models and Technologies for Intelligent Transportation Systems, 2017, pp. 839-843.

[33] Kazmer, M. M. and B. Xie, “Qualitative Interviewing in Internet Studies: Playing with the media, playing with the method", Information, Communication \& Society, 11(2), pp. 257-278.

[34] Mayring, P., "Qualitative Content Analysis”, Forum: Qualitative Social Research, 1(2), 2000, http://www.qualitative-research.net/index.php/fqs/ article/view/1089/2385.

[35] Guérin, E., E. Bales, S. Sweet, and M. Fortier, “A meta-analysis of the influence of gender on selfdetermination theory's motivational regulations for physical activity”, Canadian Psychology/Psychologie canadienne, 53(4), 2012, pp. 291-300.

[36] Gray, M. L. and Suri, S., Ghost Work - How to Stop Silicon Valley from Building a New Global Underclass, Houghton Mifflin Harcourt, New York, NY, 2019.

[37] Thomée, S., A. Härenstam, and M. Hagberg, "Mobile phone use and stress, sleep disturbances, and symptoms of depression among young adults--a prospective cohort study”, BMC Public Health, 11(66), 2011, pp. $1-11$. 